Article

\title{
Sustainable Product Development for Accessible Tourism: Case Studies Demonstrating the Need for Stakeholder Collaboration
}

\author{
Joachim Josef Nigg * and Sarah Eichelberger (D) \\ Department of Strategic Management, Marketing and Tourism, University of Innsbruck, Karl-Schönherr-Straße 3, \\ 6020 Innsbruck, Austria; sarah.eichelberger@uibk.ac.at \\ * Correspondence: joachim.nigg@uibk.ac.at; Tel.: +435-1250-772-456
}

Citation: Nigg, J.J.; Eichelberger, S. Sustainable Product Development for Accessible Tourism: Case Studies Demonstrating the Need for Stakeholder Collaboration. Sustainability 2021, 13, 11142. https://doi.org/10.3390/ su132011142

Academic Editors: Julia N. Albrecht and Marco Haid

Received: 15 September 2021

Accepted: 6 October 2021

Published: 9 October 2021

Publisher's Note: MDPI stays neutral with regard to jurisdictional claims in published maps and institutional affiliations.

Copyright: (c) 2021 by the authors. Licensee MDPI, Basel, Switzerland. This article is an open access article distributed under the terms and conditions of the Creative Commons Attribution (CC BY) license (https:// creativecommons.org/licenses/by/ $4.0 /)$.

\begin{abstract}
Sustainable tourism builds on the Sustainable Development Goals (SDGs), involving the consideration of people with disabilities, which necessitates their corresponding integration within tourism development. The noteworthy potential of accessible tourism is demonstrated in several studies. Hence, efforts have already been made to develop and adapt products in this regard. However, there are still challenges related to the inclusion of people with disabilities in tourism. Therefore, this study examines product development for accessible tourism through four case studies that have developed and implemented products for people with disabilities in the past. Data is gathered by means of qualitative interviews with managers of these product developments, and data is also triangulated with secondary information. The results show that product development for people with disabilities strongly depends on the immediate collaboration of all stakeholder groups and the inclusion of people with disabilities, building on the underlying values of the destination. Furthermore, the study indicates that in accordance with the Triple Bottom Line (TBL), sustainable product developments for accessible tourism are based on the sustainable tourism principles. Thus, both theoretical and practical implications for tourism facilities as well as for destination management organizations can be derived.
\end{abstract}

Keywords: sustainable tourism development; inclusive tourism; people with impairments; tourists with disabilities; multiple case study

\section{Introduction}

The tourism industry contributes significantly to the global economy [1], Europe being the largest tourism continent with approximately $50 \%$ of the global overnight stays in 2018 [2]. Product development in tourism is thus focused on attracting tourists to a destination. Benur and Bramwell [3] demonstrate in this context that diversified, linked, and intensified products correspond to destinations' competitiveness and sustainable development. Sustainability in tourism is represented by the sustainable tourism concept, which focuses on meeting "the needs of present tourists and host regions while protecting and enhancing opportunity for the future." [4] (p. 7) Thus, sustainable tourism addresses the balancing of economic, social and environmental tourism impacts by pursuing 17 Sustainable Development Goals (SDGs) [5], emphasizing the absence of poverty, as well as empowering less favored groups [6]. In terms of considering people with disabilities, Darcy et al. [7] place accessible tourism as a part of the social, environmental, and economic requirements for the implementation of sustainable tourism.

Accessible tourism represents an increasingly relevant segment for tourism development. While the broadly known term "barrier free tourism" concentrates explicitly on people with disabilities, "accessible tourism" takes all potential visitors of a destination into account [8]. Accordingly, the concept of accessible tourism pays heed to the "design for all" approach, which notes that all user-groups deserve holistic tourism experiences $[9,10]$. The tourism industry faces significant challenges related to the implementation of accessible 
tourism, which leads to continuous critique regarding the omnipresent exclusion of people with disabilities [11,12]. Moreover, it is argued that the huge potential for accessible tourism is still neglected in the planning and realization process of tourist facilities [13], although more than 135 million people in Europe live with disabilities [14] and the number of people at the age of 65 and older is forecast to increase from its current $20 \%$ of the population to $30 \%$ by the year 2100 [15]. Thus, referring to the UNWTO [16], accessible tourism presents an opportunity for destinations and businesses to increase their revenues by attracting new visitors.

According to Sica et al. [17], accessibility represents a central element of sustainable tourism and simultaneously provides an exceptional business opportunity for tourism facilities, which corresponds to the arguments of Sisto et al. [18] about accessible tourism representing an emerging segment of tourism demand. With regard to sustainable tourism development, travel for people with disabilities constitutes an opportunity to increase the overall quality of tourist facilities [17]. Although studies demonstrate the potential of accessible tourism [7,13], there is a lack of studies focusing on product development for people with disabilities with regard to the sustainable tourism concept. This research therefore relates to the study of accessible tourism product development as a part of sustainable tourism and focuses on the following research question:

- How can sustainable product development for accessible tourism be approached?

\section{Theoretical Framework}

\subsection{Sustainable Tourism}

Sustainable tourism is widely acknowledged in tourism research and practice, referring to tourism policy, destination management organizations (DMOs), or tourism businesses [5]. Since its emergence in the 1980s, sustainable tourism has evolved considerably, without, however, detracting from its still considerable relevance [19]. Sustainable tourism refers to a development [20] that seeks to protect both tourism communities and tourists while providing opportunities for the future [4]. In this respect, sustainable tourism builds on the SDGs as introduced by the UN 2030 Agenda for Sustainable Development [5]. The SDGs are focused on economic, environmental, and social impacts in order to reduce global poverty [21]. Sustainable tourism thus aims to achieve a balance between positive and negative impacts of tourism development, approaching the three pillars of sustainability [21,22].

However, Demeritt [23] criticizes sustainability, claiming that divergent social group interests distract attention from problematic policies by focusing on economic, social, and environmental problems in relation to the SDGs [5]. Following Higgins-Desbiolles [24], there is also a discrepancy between tourism and the SDGs, as tourism development is often still based on quantitative growth, such as the goal of increasing the number of overnight stays still being pursued. Accordingly, without considering the environmental and social impacts of tourism, the economic benefits of tourism are considered, and the SDGs are neglected accordingly. Therefore, tourism encounters environmental and social limits but continues to be geared towards growth, which requires comprehensive transformations [24]. According to Mihalic [25] sustainable tourism is based on divergent environments that underlie tourism ecology within the tourism system, referring to the Triple Bottom Line (TBL) framework [26]. The TBL is adopted by tourism organizations in an attempt to incorporate social and environmental sustainable development strategies alongside economic sustainability [26]. For Dwyer [27], the TBL provides a decision-making framework in sustainable tourism for both public and private organizations, serving as an external reporting framework and an internal management tool with the aim of achieving sustainable management by integrating social, environmental, and economic considerations into business activities. 


\subsection{Accessible Tourism}

Since the inclusion of people with disabilities in the SDGs, the importance of addressing this segment in tourism development has increased [28]. Following the SDGs, sustainable tourism focuses on the empowerment of disadvantaged groups and the prevention of poverty [6]. According to Sisto, Cappelletti, Bianchi and Sica [18], accessible tourism is a key prerequisite for all sustainable tourism strategies and policies. The consideration of people with disabilities is based on socially, economically as well as ecologically sustainable implementation [7]. Therefore, accessible tourism is an important part of the global sustainable tourism agenda, with accessible tourism being defined as a form of responsible tourism to include people with disabilities [17]. For the UNWTO [16], accessibility in tourism must be a central component of all sustainable and responsible tourism policies.

People with disabilities in the context of tourism were first reported in relation to the Paralympic games in 1960 [29]. Twenty years later, Woodside and Etzel [30] first investigated the travel behavior of people with disabilities. Since then, several concepts for bridging tourism and disability have emerged [13]. However, the tourism industry is still repeatedly criticized for its exclusive attitude [31]. This is ascribed to the fact that the requirements and needs of people with disabilities are frequently neglected in the development of tourism products and in the implementation of tourism services [12] People with different types and dimensions of disability have in common that their right to social participation is repeatedly unsatisfied [32]. Different from the broadly known concept of "barrier free" tourism, accessible tourism includes, in addition to people with disabilities, seniors, families, pregnant women, and people with temporary disabilities [13]. In this regard, Dickson et al. [33] conclude that everyone with or without disability will appreciate accessibility once in a lifetime. Moreover, people with disabilities are commonly accompanied by their colleagues or families when travelling and show a high rate of return if destinations fit their accessibility requirements [34]. Due to demographic changes, there is also an increasing number of seniors travelling, who show, due to retirement, a low seasonal dependency $[15,35]$. Thus, accessible tourism development promises a considerable potential.

To foster the development of accessible tourism, different tourism stakeholders need to share similar perceptions on people with disabilities [36]. In this regard, Oliver [31] highlights the differentiation between the medical and the social model of disability. The medical approach to disability, which is still predominant in Europe, refers to disability as a result of limited functioning in moving, hearing, seeing, or learning [13,31]. This is equivalent to a former statement by the WHO [37] which referred to disabilities as individual problems that trigger obstacles in a natural manner. In contrast to that, the social model of disability refers to disabilities as a result of societal evolution and perceives disability as a social construct that excludes people with disabilities from social participation [31]. Over the past 40 years, the perspective of the WHO on disabilities has shifted to accord with the social model of disability [14]. However, to trigger a shift towards the social perspective on disabilities in society, a collective campaign action for change is fundamental [38]. McIntosh [11] concludes that such a collective campaign can be achieved by sustainable tourism development for all. According to the UNWTO [39], the COVID-19 pandemic can serve as a trigger for the development of good accessibility for persons with disabilities to combat the negative effects of the crisis.

\subsection{Product Development for Sustainable Tourism}

Tourism products are developed to meet the needs of potential consumers [40] and thus attract tourists to destinations [3]. In this context, tourism products consist of five elements: hospitality, service, inclusion, choice, and physical plant [41], which are all pull factors aimed at motivating tourists [3]. Referring to Smith [41], product development in tourism is characterized by raw inputs being the beginning of generic production, followed by intermediate outputs and inputs leading to tourists' experiences as final output. Successful integration of the five elements thus leads to the development of a 
product that is designed to attract tourists' attention and satisfy their needs [40]. Following Shuhsien et al. [42], knowledge about the patterns of consumer demand, consumer preferences, as well as tourism flow is required for strategic tourism product development. Referring to Benur and Bramwell [3], tourism product linkage, diversification, and intensification are crucial for sustainable development, as well as for destination competitiveness. Thus, tourism products are developed for both mass and niche markets to improve diversification [3].

For Benur and Bramwell [3], sustainable development can be supported by developing a mix of tourism products that are mutually beneficial and have collaborative relationships. Thus, profitable products that meet strategic objectives potentially contribute to sustainability [3]. Following Eckert and Pechlaner [43], diversification in the form of tourism products is therefore necessary to develop sustainability in tourism. In this regard, a product development approach is targeted to contribute to sustainable tourism. Thus, the coexistence of alternative as well as traditional tourism products is discussed, with a focus on going beyond existing tourism models by focusing on themes and values that characterize a destination. The tourism products help to address destination challenges, for example, by considering the local community as well as dealing with environmental issues [43], in line with the sustainable tourism concept [21]. Haid and Albrecht [44] show that products for sustainable tourism can be developed by adjusting distribution channels and supply chains with the introduction of a sustainability requirement.

Following the TBL approach, individual businesses play an important role in the development of sustainable tourism [27]. Darcy, Cameron and Pegg [7] linked accessible tourism to the TBL framework by identifying economic, social, and environmental aspects of accessible tourism. In this respect, accessible tourism is based on a set of social networks of destinations rather than individual tourism organizations. Thus, Darcy, Cameron and Pegg [7] advocate the development of an accessible destination experience to satisfy the tourism market. A key objective of the TBL is that performance is not based solely on shareholder benefits, but rather on the inclusion of all stakeholders, including groups such as community residents [26]. The central meaning of stakeholder collaboration in project management is emphasized by several authors $[45,46]$. Although stakeholder collaboration is considered an important tool to foster the destination image in tourism management in a sustainable manner [47], this is found to be complex and scarce [48]. Gillovic and McIntosh [10] identified a lack of stakeholder collaboration in the development of accessible tourism. In addition, Nyanjom et al. [49] concluded that there is only minimal collaboration among different stakeholder groups in the development of accessible facilities. However, according to the UNWTO [50], the cooperation of all public and private stakeholders is required to implement accessibility, placing destinations at the centre of all tourism activities and thus being seen as promoters and disseminators of accessible tourism.

Thus, building on the TBL, this research focuses on product development with objectives of environmental protection, economic prosperity, and social responsibility [51,52]. According to Mattioda, Fernandes, Detro, Casela and Canciglieri Junior [52], research on product development in light of the TBL concept is still at an initial stage, making further research necessary. Furthermore, as Haid and Albrecht [44] recommend studying sustainable tourism product development for particular types of tourist products, this research focuses on products for people with disabilities, in line with the accessible tourism approach.

\section{Materials and Methods}

Even though the use of business cases is considered a good tool for raising awareness of the potential of accessible tourism, their application is still underdeveloped [7,18]. Darcy, Cameron and Pegg [7] (p. 533) conclude that "until examples of good business practice are identified and promoted, the industry cannot be guided with certainty about the benefits in providing expanded accessible tourism products". Thus, a multiple case study method is adopted, which is particularly useful when developing an understanding of real-life 
phenomena $[53,54]$. In collaboration with organizations for people with disabilities in Italy and Austria, four leisure parks as tourist facilities in Central Europe were selected. The choice was based on three criteria. First, the facilities had to offer products for accessible tourism that were developed in the recent past. Second, facilities that are characterized by nature experiences were regarded. Third, the institutions were proved to have a maximum number of 15 employees. Thus, a purposive sampling technique was applied. For each tourist facility, two representatives involved in the product development process were interviewed, as Haid and Albrecht [44] recommended including owners or operators in studies on product development for sustainable tourism. The interviews lasted an average of $77 \mathrm{~min}$ and were conducted online via Zoom due to the COVID-19 pandemic and consequent travel restrictions. The interview guideline was developed based on existing research on sustainable tourism [19-22], accessible tourism [7,13,18,28], and product development $[3,41,43,44]$ literature. In this regard, questions regarding the process of product development, its implementation, and its completion were asked as key themes of the interview guideline. The semi-structured interviews made it possible to delve deeply into the experiences of the interviewees [55], and the data was triangulated [56] with publicly available information about the products developed, e.g., from the websites of the tourist facilities. Organization-specific data including the location and size of the organization and the position of the interviewee [57] (see Table 1) was collected by the authors.

Table 1. Overview of interviewees.

\begin{tabular}{|c|c|c|c|c|}
\hline Code & Region & $\begin{array}{l}\text { Size of the } \\
\text { Organization }\end{array}$ & Position & Gender \\
\hline TF1_1 & South Tyrol & 12 employees & Tourist facility manager & Male \\
\hline TF1_2 & South Tyrol & 12 employees & Product development manager & Male \\
\hline TF2_1 & $\begin{array}{l}\text { Vicenza } \\
\text { Province }\end{array}$ & 7 employees & Tourist facility manager & Female \\
\hline TF2_2 & $\begin{array}{l}\text { Vicenza } \\
\text { Province }\end{array}$ & 7 employees & Product development manager & Male \\
\hline TF3_1 & $\begin{array}{l}\text { Belluno } \\
\text { Province }\end{array}$ & 11 employees & Tourist facility manager & Female \\
\hline TF3_2 & $\begin{array}{l}\text { Belluno } \\
\text { Province }\end{array}$ & 11 employees & Product development manager & Female \\
\hline TF4_1 & Salzburg & 8 employees & Tourist facility and product development manager & Male \\
\hline TF4_2 & Salzburg & 8 employees & Product development employee & Male \\
\hline
\end{tabular}

The data were analyzed following the template analysis approach of King [58]. In an attempt to pursue a facilitated and systematic data analysis process, MAXQDA was used as qualitative data analysis software. Following the template analysis, the two authors collaboratively developed an initial coding template with a priori themes and a priori codes being defined on the basis of previous studies. In order to enhance the quality of the data analysis, after an evaluation of the interview data, the coding template was revised separately by the researchers. A discussion about parallel findings resulted in a rewording and redefinition of the final coding template. Thus, critical comparison between the two researchers, alongside the independent coding, made it possible to modify the template and thus enhance the overall quality of this research [58,59]. Additionally, all divergent interviewees' opinions were incorporated in the data analysis process in order to enhance the objectivity of the research [60].

\section{Results}

\subsection{Values}

Both the secondary data and the interview analysis reveal that all the tourist facilities researched convey similar core values for their regions. One such major element is nature, which is displayed prominently on all four tourist facilities' websites. Thus, central to all participants is to provide the best possible nature experience by "building everything 
on the relation between the person and nature" (TF2_2_10). Similar philosophies can be seen with regard to the consideration of nature in the destinations. Here, the interviewees show that they use nature as a basis on which to build their product developments: "One thing that we tried was to develop a product, that is to build on the relationship between the park and nature. [ ... ] he felt that the product actually gives him the opportunity to experience this relationship" (TF2_1_23). In addition to that, three of the four regions convey cultural and historical backgrounds: "The most important requirement was that it should be an immersive experience of the World Heritage Site [ . . ] and bring added value. That was the initial situation" (TF1_1_3). Finally, the analysis of the websites results in the conclusion that leisure is the central anchor of all these tourist facilities. Thus, they display leisure activities for both guests and residents.

In the course of the respective product developments, the participating regions' values, namely, nature, culture, and leisure experiences, were to be made available to people with disabilities. However, the developments at the tourist facilities were not meant to be supportive solely of people with disabilities but were also for people without disabilities. "In this respect, it is a technology or an application that brings something to all visitors and has been developed on a broad basis." (TF1_2_3). Furthermore, according to the interviewees, value should be created in terms of opportunities and alternatives, as this quote shows: "We don't just want to make something that is useful for people or visitors with a walking disability, but it is important to us that this visitor platform at the top is an added value for days when it rains, or out of season-when there is perhaps a winter closure, where it is too icy or too slippery to enter the gorge" (TF1_1_3).

Retrospectively, the lessons learned from working on the inclusion of people with disabilities are twofold. While the tourist facilities mainly stated that they would realize the product development in a similar manner again, there are still some issues related to that. To increase the sustainability of the implementation process, suppliers would have needed to receive a deeper briefing on the core themes of the respective facilities and destinations. Such takeaways made participants conclude that "[ ... ] if I had to make another trail of perception now, I would be less clueless. So, I would have already a method because as we showed during our presentation, now we have kind of a model" (TF3_2_24).

\subsection{Product Development}

For product development, the interviewees indicated that they tried to make the best use of the manifold potential of information provision for everyone: "We wanted to offer this new opportunity with all the physical and also technological tools and instruments to facilitate-not just facilitate, also give this experience a natural flavor" (TF3_1_1). Thus, interviewees indicated that inclusion of people with disabilities took a central role throughout the product development: "[ ... ] the focus was inclusive communication as a way to involve those who are sometimes neglected or are not taken into consideration when developing this kind of product, which means especially that deaf people or people with visual impairments, but also pregnant mothers, children, as well as old people are to be regarded" (TF2_1_9). The applications were planned in a way that should enhance the ability of people with disabilities to experience the facilities and regions on their own. "Actually, the trail of perceptions in some segments of the trail allows the visually impaired people and also people in wheelchairs to have the experience all alone. So, this is another very important aspect which is very positive for people with disabilities" (TF3_1_3).

Throughout the product's development, feedback from the target groups was described as essential: "The two visually impaired ladies told us that there might be some points-where there is water, that could be a little bit difficult. But if you have someone who will show you where to put your feet, it is no problem" (TF3_1_3). In addition, feedback from H\&T service providers as promoters of the product was requested in the way that "we have sent it to 31 hotels of medium and large size. [ . . . ] We asked all of them for some feedback where the managers were asked to describe if it fits their requirements or not" (TF4_1_17). To reach the best possible outcome, the feedback was taken into consideration 
and brought up the relevant consequences regarding further development. For instance, infographics were adjusted, special virtual reality effects were reduced, the web app was enhanced with new features, and the contrast level in illustrations was adapted. These improvements, however, did not always work out as expected beforehand and led to several drawbacks for the parties responsible. One such was caused by bureaucracy, e.g., "We may have 8 different info-panels in 8 municipalities, and I have to get the permission of 8 different municipalities before I install a sign anywhere" (TF1_2_29).

In terms of the product development phase, the most important lesson learnt at the four tourist facilities is aimed at stakeholder collaboration: "They were working together, and they were not just working on it in an isolated way. So, they were not just working on this and that. They were all working together, updating each other" (TF2_2_38). Accordingly, the fusion of different interests is described as an essential tool for fostering a sustainable product development. To avoid conflicts between the parties involved, clarity of roles is of vital importance. In particular, the development of accessible implementations is characterized as a "multidisciplinary system of work, which brings together different competences, such as narratives, as well as IT and accessibility experts" (TF2_2_38). On the one hand, it is important to "[ ... ] have suppliers that are aware that they are doing something for a particular target group" (TF3_2_22). On the other hand, there are stakeholder groups that are in a position to put greater pressure on accessible tourism development than others, as this quote shows: "We do not have a mandate. There must be entities that have a mandate involved [ ... ] for example representatives of people with disabilities or organizations for people with disabilities" (TF4_2_86). In addition to the involvement of stakeholder groups, such as H\&T service providers, volunteers, municipalities, and suppliers, the continuous involvement of the target groups is fundamental in order to take account of all the potential requirements of people with disabilities throughout the development process: "The main aspect is to involve the specific target group that you are working for, because they can, in certain cases, change a lot the perspective that you have and that you think is the right one. And so, they can help you to avoid making big mistakes that maybe cannot be solved, if you do not involve them from the beginning" (TF3_2_22).

COVID-19 had several impacts on the product development process for the tourist facilities: "During coronavirus, we had some delays, some significant delays due to the fact that suppliers were not able to work, or they were supplied or expecting supplies of goods from different countries with border problems" (TF2_2_50). To catch up again, "we asked to prolong the end of the project. But the lead partner informed us that it was not possible" (TF3_2_28). In addition to that, the pandemic situation led to limited financial resources, which forced the tourist facilities to concentrate on their core competences and required that "[ ... ] the visitor survey be in some way suspended or executed in a reduced form this year" (TF1_1_76). In addition to issues related to the pandemic situations, limited resources were also mentioned: "There you can insert many new trails and provide even more detailed descriptions. However, this would have required much more effort which we were not able to afford" (TF4_1_4).

\subsection{Products}

For the products themselves, the major ingredient for the tourist facilities was the adaptation of digitalization techniques to the manifold requirements of people with disabilities: "So, as much technology as possible and not just for the sake of using it, but of course to involve as many people as possible" (TF2_1_9). Thus, websites and web apps were adapted to the accessible web design guidelines: "Of course, there are these web content accessibility guidelines. In the case of public authorities, they have a very strong obligation to implement them. However, if you are a hotel or something similar, you are not forced to implement web accessibility" (TF4_1_67). Thus, the tourist facilities implemented a variety of digital tools to increase accessibility of their facilities. Virtual reality, web applications, iBeacons, a chatbot, parking spot sensors to inform visitors about availability, 
and information platforms are some examples of these. In addition, the development of a tactile model of a building is one example of an analogue implementation.

The responsible parties generally received rewarding feedback from their visitors on the final product, as this example for the virtual reality application shows: "Interestingly, everyone was always stunned that it works so well and how well you can empathize your surroundings! It was quite exciting to see how people reacted. So, I see a very promising future here" (TF1_1_4). Due to the restrictions related to the COVID-19 pandemic, however, some tourist facilities have not yet been able to gain sufficient feedback on their implementations. For this reason, several implementations are to be tested in the framework of upcoming trials "[ ... ] to see how the technologies developed are perceived and also very briefly, to find out how the chatbot works, did the user/visitor notice its existence at all? Did he also use the path above? Or use the app? That you could ask the visitor two or three short questions about the technologies developed in the project and include those in the questionnaire. COVID-19 in particular has been a topic again" (TF1_2_76). However, such trials rely on an improvement in the pandemic situation.

Building on the implementation of the given product developments, all participants are planning further adaptions and developments of their products: "At the moment, one potential implementation would be an additional point of interest, but from the technical point of view, the web app at the moment is not expected to be further developed in the technical way" (TF3_2_17). One interviewee, however, explained that his facility does not have the required resources to develop the given information platform further and mentioned that he has to "[ ... ] clarify this first with the H\&T service providers of the region if they would like to take over responsibility for the platform. [ ... ] Otherwise, we let this thing expire next year" (TF4_1_43). This is due to the fact that the resources for further maintenance of the platform are not available.

\section{Discussion}

The various case studies exposed manifold patterns of sustainable product development for accessible tourism. The results show that the similar sized tourist facilities refer to similar core values and build their product developments on these values. In this regard, the values were 'nature', 'culture', and 'leisure'. Referring to Eckert and Pechlaner [43], the values represent core competencies and serve in terms of a resource-based view as foundations for product development. Correspondingly, product developments should be in close harmony with the core values of a destination. The results of this multiple case study show that the tourism facilities address their own values, as well as those of the destination in which the facility is located. In addition, the findings show that product developments can even be anchored in these values. Inferentially, it can be assumed that the tourism facilities can contain the issue of inclusion in their values and thus pursue a philosophy [43] of attempting to pursue accessible tourism as a prerequisite for sustainable tourism strategies [18].

Proposition 1. Sustainable product development for accessible tourism should be based on the core values of a destination and serve as a philosophy.

Furthermore, in the spirit of the philosophy, the results clearly show that not only are people with disabilities are taken into account but that all persons were considered in relation to the product developments. This is in line with the conclusion of Dickson, Darcy and Walker [33] who state that everyone will appreciate accessibility once in a while, referring to seniors, families, people with temporary disabilities, or, for instance, pregnant women [13]. In this regard, the interviewees stress that there is an urgent need to enhance the experience of nature facilities for everyone in a spirit of social inclusion [32]. It can be deduced from the results that the inclusion of everyone is fundamental and thus, in the sense of Eckert and Pechlaner [43], a key competence. Accordingly, the interviewees indicate that they integrate social considerations in their development [27], which corresponds to the social sustainable development strategy of the TBL [26]. On this 
assumption, the tourist facilities investigated in this study apparently maintain a social awareness of people with disabilities [13,31].

Proposition 2. Tourism for all, as a factor of social sustainable tourism, represents a central value for product development for accessible tourism.

Moreover, the results specify that an added value is targeted in accordance with economic sustainability $[22,26]$ by providing alternative offers, such as for non-seasonal times. In this regard, the financial wealth of accessible tourism development is considered by tourism facilities [34] to achieve economic prosperity in line with the TBL [51,52]. Thus, the inclusion of people with disabilities as a target group is anchored in the strategies of the tourist facilities [28] to meet their own objectives and potentially contribute to sustainability [3].

Proposition 3. In addition to the social aspect of sustainable tourism development, economic sustainability, with the goal of value creation, plays a decisive role in product development for accessible tourism.

In addition to that, the case studies reveal that the interviewees regard nature as a cornerstone of their product developments, which in turn is linked to environmental sustainability [26]. In line with Eckert and Pechlaner [43], nature represents a core competence of the destinations. To conquer discrimination of people with disabilities in such nature areas, where accessibility is not easily deployable, new means of digitalization potentially enhance the opportunity for people with disabilities to experience societal inclusion [31]. Accordingly, implementations such as virtual reality applications and iBeacon applications can potentially avoid the need for adaptions of hiking paths or information boards in sensitive regions of nature. Thus, diversification in the form of new tourism products is created, from which mutual benefits are gained in an environmental sustainable manner $[3,43]$. Alongside this, the implementation of such environmentally friendly accessible tourism products supports sustainable tourism development [44].

Proposition 4. Digitalization can serve as an enabler for sustainable product development for accessible tourism, making nature accessible to people with disabilities and thus contributing to environmental sustainability.

Thus, it can be deduced that the interviewees refer to the three pillars of sustainability in sustainable product development for accessible tourism; in TBL terms, social, ecological and economic sustainability are cemented [26]. This corresponds to Darcy, Cameron and Pegg [7] who state that project development in accessible tourism has to consider all pillars of sustainability. As the interviewees broadened their scope from tourism for people with disabilities to tourism for everyone, the findings reveal that accessibility represents a prerequisite for sustainable tourism development in general [18].

Furthermore, the findings demonstrate that stakeholder collaboration is essential to the development of sustainable products for people with disabilities [36], highlighting the importance of blending different perspectives towards a project target [13]. Thus, feedback from people with disabilities and feedback from different stakeholders are important components of sustainable product development for accessible tourism. The interviewees value stakeholder management which should be arranged in such a way that every participating party takes responsibility for its own expertise while standing in fluent exchange with the other stakeholder groups [49]. In addition to H\&T service providers, municipalities, organizations for people with disabilities, and residents, the inclusion of the target group is stressed to be one critical aspect for product development success [10]. With their inclusion right from the beginning, the manifold requirements of people with disabilities are potentially taken into account in sustainable product development [12]. Additionally, the findings illustrate that the tourist facilities were confronted with several issues such 
as delays, staffing limitations, financial shortages, and limited opportunities to gather feedback related to the COVID-19 pandemic. These and other constraints related to the pandemic can potentially be overcome if cooperation between all stakeholders is properly controlled.

Proposition 5. Stakeholder collaboration, especially with the inclusion of people with disabilities, is an effective tool for successful sustainable product development for accessible tourism.

\section{Conclusions}

This study examined product development from a sustainability perspective for accessible tourism. Hence, it contributes to sustainable tourism, accessible tourism, and product development literature. Figure 1 illustrates in this regard the derived results. On the basis of the case study findings it can be deduced that sustainable product development, in TBL terms [26], is based on the three principles of sustainability [25] and accordingly social, economic, and ecological sustainability are considered in product development. Priority is given to tourism for all as a social factor, the development of value in terms of economic sustainability, and nature as part of environmental sustainability. Furthermore, sustainable product development concentrates on the underlying values of the tourist facilities and the destinations [43], focusing in these cases on nature, culture and leisure. The process of sustainable product development is also based on the involvement of people with disabilities as well as collaboration with various stakeholders. Feedback from people with disabilities as well as, for instance, from H\&T service providers, municipalities, organizations for people with disabilities and residents is used to develop the products specifically aimed at the target group [13]. Furthermore, the findings of this study suggest that the products developed for people with disabilities can in turn be included as values that serve as a philosophy. Accordingly, accessibility as a value can then represent a basis for further sustainable product developments (see Figure 1).

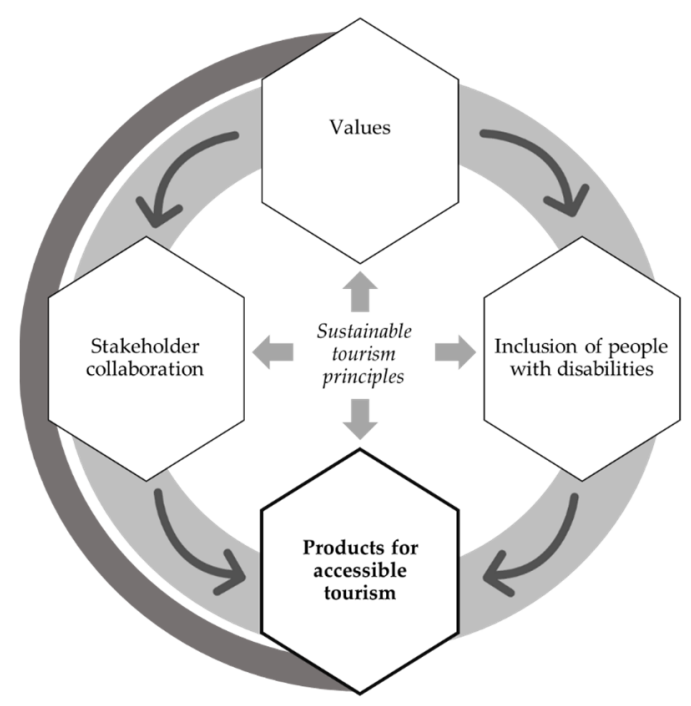

Figure 1. Sustainable product development for accessible tourism.

Aside from this, the multiple case study approach makes it possible to derive recommendations for tourism practice. On the one hand, these are recommendations for tourism facilities that pursue sustainable product development in the field of accessible tourism, and on the other hand, recommendations for tourism stakeholders to support product developments can be deduced. The findings show that developing products for people with disabilities requires collaborative work. According to the interviewees, the exchange of information between stakeholders, as well as discussions and the inclusion of different perspectives, leads to the best results in product development for accessible tourism. In 
this sense, the tourism facilities are challenged to integrate people with disabilities into the product development process on one side and to consider stakeholders and their opinions for products on the other side. Here, for example, DMOs can play a mediating role and enable feedback and integration by bringing together different stakeholders. In addition, joint development with the DMO can then also enable the inclusion of accessibility in the values and corresponding further sustainable product developments in accessible tourism can be sought. Furthermore, there should be a focus on the inclusion of people with disabilities in the product development throughout the entire development process, while feedback regarding possible adaptations and further developments should be also considered after final completion.

The results of the study explicitly contribute to a better understanding of sustainable product development for accessible tourism. However, the qualitative research character of the study limits the generalizability of the results, making further quantitative research on accessible tourism and sustainable product development necessary. Longitudinal studies are recommended to monitor the implementation and further development of sustainable products for people with disabilities, and to include additional product developments or adaptations and adjustments. In addition, future studies can address stakeholder collaboration and explore interactions and partnerships comprehensively through qualitative studies. As this study refers to four cases in destinations with similar core competencies, the characteristics of the destinations represent a limitation of the study, which leads to a recommendation that further studies should include other divergent destinations. In addition, the development of the products and their implementation was influenced by the COVID-19 crisis, which will influence future research opportunities after the pandemic.

Author Contributions: Conceptualization, J.J.N. and S.E.; methodology, J.J.N. and S.E.; software, J.J.N.; validation, S.E.; formal analysis, J.J.N. and S.E.; investigation, J.J.N.; resources, J.J.N. and S.E.; data curation, J.J.N.; writing-original draft preparation, J.J.N. and S.E.; writing-review and editing, J.J.N. and S.E.; visualization, J.J.N. and S.E.; supervision, J.J.N.; project administration, J.J.N. and S.E.; funding acquisition, J.J.N. and S.E. All authors have read and agreed to the published version of the manuscript.

Funding: The authors would like to thank the University of Innsbruck for supporting this open access publication. It was published with financial support from the Vice Rectorate for Research of the University of Innsbruck.

Institutional Review Board Statement: Not applicable.

Informed Consent Statement: Not applicable.

Data Availability Statement: Not applicable.

Acknowledgments: We would like to thank Nick Tanner for the proofread of the paper.

Conflicts of Interest: The authors declare no conflict of interest.

\section{References}

1. WTTC. Economic Impact Reports. Available online: https://wttc.org/Research/Economic-Impact (accessed on 29 October 2020).

2. UNWTO. International Tourism Highlights. Available online: https://www.e-unwto.org/doi/pdf/10.18111/9789284421152 (accessed on 15 August 2021).

3. Benur, A.M.; Bramwell, B. Tourism product development and product diversification in destinations. Tour. Manag. 2015, 50, 213-224. [CrossRef]

4. WTO. Sustainable Tourism Development: Guide for Local Planners; WTO: Madrid, Spain, 1993.

5. Hall, C.M. Constructing sustainable tourism development: The 2030 agenda and the managerial ecology of sustainable tourism. J. Sustain. Tour. 2019, 27, 1044-1060. [CrossRef]

6. UNWTO. Tourism for SDGs. Available online: https://tourism4sdgs.org/sdg-1-no-poverty / (accessed on 15 June 2021 ).

7. Darcy, S.; Cameron, B.; Pegg, S. Accessible tourism and sustainability: A discussion and case study. J. Sustain. Tour. 2010, 18, 515-537. [CrossRef]

8. Allan, M. Disability tourism: Why do disabled people engaging in tourism activities. Eur. J. Soc. Sci. 2013, 39, 480-486.

9. Aslaksen, F.; Bergh, S.; Bringa, O.R.; Heggem, E.K. Universal Design: Planning and Design for All. Available online: https: / / hdl.handle.net/1813/76583 (accessed on 14 June 2021). 
10. Gillovic, B.; McIntosh, A. Stakeholder perspectives of the future of accessible tourism in New Zealand. J. Tour. Futures 2015, 1, 223-239. [CrossRef]

11. McIntosh, A.J. The hidden side of travel: Epilepsy and tourism. Ann. Tour. Res. 2020, 81, 102856. [CrossRef]

12. Scheyvens, R.; Biddulph, R. Inclusive tourism development. Tour. Geogr. 2018, 20, 589-609. [CrossRef]

13. Buhalis, D.; Darcy, S. Accessible Tourism. Concepts and Issues; Channel View Publications: Bristol, UK, 2011.

14. WHO. Disability. Available online: https://www.euro.who.int/en/health-topics/Life-stages/disability-and-rehabilitation/ areas-of-work/disability (accessed on 14 June 2021).

15. Eurostat. Population Related to Age. Available online: https://ec.europa.eu/eurostat/databrowser/view/tps00010/default/ table?lang=de (accessed on 11 September 2020).

16. UNWTO. Accessible Tourism. Available online: https://www.unwto.org/accessibility (accessed on 3 October 2021).

17. Sica, E.; Sisto, R.; Bianchi, P.; Cappelletti, G. Inclusivity and Responsible Tourism: Designing a Trademark for a National Park Area. Sustainability 2021, 13, 13. [CrossRef]

18. Sisto, R.; Cappelletti, G.M.; Bianchi, P.; Sica, E. Sustainable and accessible tourism in natural areas: A participatory approach. Curr. Issues Tour. 2021, 1-18. [CrossRef]

19. Ruhanen, L.; Moyle, C.-1.; Moyle, B. New directions in sustainable tourism research. Tour. Rev. 2019, 74, 138-149. [CrossRef]

20. Guaita Martínez, J.M.; Martín Martín, J.M.; Salinas Fernández, J.A.; Mogorrón-Guerrero, H. An analysis of the stability of rural tourism as a desired condition for sustainable tourism. J. Bus. Res. 2019, 100, 165-174. [CrossRef]

21. Bramwell, B.; Higham, J.; Lane, B.; Miller, G. Twenty-five years of sustainable tourism and the Journal of Sustainable Tourism: Looking back and moving forward. J. Sustain. Tour. 2017, 25, 1-9. [CrossRef]

22. Purvis, B.; Mao, Y.; Robinson, D. Three pillars of sustainability: In search of conceptual origins. Sustain. Sci. 2019, 14, 681-695. [CrossRef]

23. Demeritt, D. The Construction of Global Warming and the Politics of Science. Ann. Assoc. Am. Geogr. 2001, 91, 307-337. [CrossRef]

24. Higgins-Desbiolles, F. Sustainable tourism: Sustaining tourism or something more? Tour. Manag. Perspect. 2018, 25, 157-160. [CrossRef]

25. Mihalic, T. Conceptualising overtourism: A sustainability approach. Ann. Tour. Res. 2020, 84, 103025. [CrossRef]

26. Stoddard, J.E.; Pollard, C.E.; Evans, M.R. The Triple Bottom Line: A Framework for Sustainable Tourism Development. Int. J. Hosp. Tour. Adm. 2012, 13, 233-258. [CrossRef]

27. Dwyer, L. Relevance of triple bottom line reporting to achievement of sustainable tourism: A scoping study. Tour. Rev. Int. 2005, 9, 79-938. [CrossRef]

28. Darcy, S.; McKercher, B.; Schweinsberg, S. From tourism and disability to accessible tourism: A perspective article. Tour. Rev. 2020, 75, 140-144. [CrossRef]

29. Darcy, S.; Lock, D.; Taylor, T. Enabling Inclusive Sport Participation: Effects of Disability and Support Needs on Constraints to Sport Participation. Leis. Sci. 2017, 39, 20-41. [CrossRef]

30. Woodside, A.G.; Etzel, M.J. Impact of physical and mental handicaps on vacation travel behavior. J. Travel Res. 1980, 18, 9-11. [CrossRef]

31. Oliver, M. Understanding Disability, 2nd ed.; Palgrave Macmillan: New York, NY, USA, 2009.

32. Domínguez, T.; Alén, E.; Fraiz, J. International accessibility: A proposal for a system of symbols for people with disabilities. Int. J. Disabil. Hum. Dev. 2013, 12, 489. [CrossRef]

33. Dickson, T.J.; Darcy, S.; Walker, C. A Case of Leveraging a Mega-Sport Event for a Sport Participation and Sport Tourism Legacy: A Prospective Longitudinal Case Study of Whistler Adaptive Sports. Sustainability 2021, 13, 170. [CrossRef]

34. GFK. Economic Impact and Travel Patterns of Accessible Tourism in Europe; Belgium. 2014. Available online: https: / / www.google.com/url?sa=t\&rct=j\&q=\&esrc=s\&source=web\&cd=\&cad=rja\&uact=8\&ved=2ahUKEwjK1-bpzrfzAhWQg 0HHSj3D0gQFnoECAkQAQ\&url=http $\% 3 \mathrm{~A} \% 2 \mathrm{~F} \% 2 \mathrm{Fwww}$.accessibletourism.org $\% 2$ Fresources $\% 2 \mathrm{Ftoolip} \% 2 \mathrm{Fdoc} \% 2 \mathrm{~F} 2014 \% 2 \mathrm{~F} 0$ 6\%2F09\%2Fguisette-and-li_eu-accessible-tourism_economic-demand-study.pdf\&usg=AOvVaw3I8xiXtKSNkG7pkK4NAXcQ (accessed on 3 October 2021).

35. Eurostat. Tourism Trends and Ageing. Available online: https://ec.europa.eu/eurostat/statistics-explained/index.php/ Tourism_trends_and_ageing\#Seasonal_patterns (accessed on 27 August 2020).

36. Bailey, K. Learning more from the social model: Linking Experience, Participation and Knowledge Production. In Implementing the Social Model of Disability: Theory and Research; Barnes, C., Mercer, G., Eds.; Disability Press: Leeds, UK, 2004.

37. WHO. International Classification of Impairments, Disabilities, and Handicaps; WHO: Geneva, Switzerland, 1980.

38. Putnam, M. Conceptualizing Disability. J. Disabil. Policy Stud. 2005, 16, 188-198. [CrossRef]

39. World Tourism Organization. UNWTO Inclusive Recovery Guide-Sociocultural Impacts of Covid-19, Issue I: Persons with Disabilities; UNWTO: Madrid, Spain, 2020.

40. Xu, J.B. Perceptions of tourism products. Tour. Manag. 2010, 31, 607-610. [CrossRef]

41. Smith, S.L.J. The tourism product. Ann. Tour. Res. 1994, 21, 582-595. [CrossRef]

42. Shu-hsien, L.; Yin-Ju, C.; Min-yi, D. Mining customer knowledge for tourism new product development and customer relationship management. Expert Syst. Appl. 2010, 37, 4212-4223. [CrossRef]

43. Eckert, C.; Pechlaner, H. Alternative Product Development as Strategy Towards Sustainability in Tourism: The Case of Lanzarote. Sustainability 2019, 11, 3588. [CrossRef] 
44. Haid, M.; Albrecht, J.N. Sustainable Tourism Product Development: An Application of Product Design Concepts. Sustainability 2021, 13, 7957. [CrossRef]

45. Chen, L.; Zhao, X.; Tang, O.; Price, L.; Zhang, S.; Zhu, W. Supply chain collaboration for sustainability: A literature review and future research agenda. Int. J. Prod. Econ. 2017, 194, 73-87. [CrossRef]

46. Renger, M.; Kolfschoten, G.L.; Vreede, G.J. Challenges in collaborative modelling: A literature review and research agenda. Int. J. Simul. Process. Model. 2008, 4, 248. [CrossRef]

47. Buhalis, D.; Ambrose, I.; Darcy, S.; Michopoulou, E. Accessible Tourism Futures: The World we Dream to Live in and the Opportunities We Hope to Have; Emerald: Bingley, UK, 2015; Volume 1.

48. Waligo, V.M.; Clarke, J.; Hawkins, R. Implementing sustainable tourism: A multi-stakeholder involvement management framework. Tour. Manag. 2013, 36, 342-353. [CrossRef]

49. Nyanjom, J.; Boxall, K.; Slaven, J. Towards inclusive tourism? Stakeholder collaboration in the development of accessible tourism. Tour. Geogr. 2018, 20, 675-697. [CrossRef]

50. UNWTO. Manual on Accessible Tourism for All: Principles, Tools and Best Practices-Module V: Best Practices in Accessible Tourism; Madrid. Available online: https:/ / webunwto.s3.eu-west-1.amazonaws.com/s3fs-public/2020-04/modulev13022017. pdf (accessed on 3 October 2021).

51. Bataglin, M.; Ferreira, J.C.E. A modularization method based on the triple bottom line and product desirability: A case study of a hydraulic product. J. Clean. Prod. 2020, 271, 122198. [CrossRef]

52. Mattioda, R.A.; Fernandes, P.T.; Detro, S.; Casela, J.L.; Canciglieri Junior, O. Principle of Triple Bottom Line in the Integrated Development of Sustainable Products. Chem. Eng. Trans. 2013, 35, 199-204. [CrossRef]

53. Eisenhardt, K.M. Building Theories from Case Study Research. Acad. Manag. Rev. 1989, 14, 532. [CrossRef]

54. Eisenhardt, K.M.; Graebner, M.E. Theory Building From Cases: Opportunities And Challenges. Acad. Manag. J. 2007, 50, 25-32. [CrossRef]

55. Rowley, J. Conducting research interviews. Manag. Res. Rev. 2012, 35, 260-271. [CrossRef]

56. Decrop, A. Triangulation in qualitative tourism research. Tour. Manag. 1999, 20, 157-161. [CrossRef]

57. Bowen, G.A. Document Analysis as a Qualitative Research Method. Qual. Res. J. 2009, 9, 27-40. [CrossRef]

58. King, N. Doing Template Analysis. In Qualitative Organizational Research: Core Methods and Current Challenges; Symon, G., Cassell, C., Eds.; SAGE Publications Inc.: London, UK, 2012; pp. 426-450.

59. King, N.; Brooks, J.M. Template Analysis; SAGE: Los Angeles, CA, USA, 2017.

60. Madill, A.; Jordan, A.; Shirley, C. Objectivity and reliability in qualitative analysis: Realist, contextualist and radical constructionist epistemologies. Br. J. Psychol. 2000, 91, 1-20. [CrossRef] [PubMed] 